\title{
Theorizing Teachers' Perspectives on an EFL Textbook for Public High Schools of Iran: A Grounded Theory
}

\author{
Seyyed Ali Ostovar Namaghi ${ }^{1}$, Mohammad Reza Saboor Moghaddam ${ }^{1} \&$ Maryam Tajzad $^{1}$ \\ ${ }^{1}$ Shahrood University of Technology, Iran \\ Correspondence: Seyyed Ali Ostovar Namaghi, Shahrood University of Technology, Iran. E-mail: \\ saostovarnamaghi@yahoo.com
}

\author{
Received: May 7, 2014 Accepted: September 3, 2014 Online Published: September 28, 2014 \\ doi:10.5539/elt.v7n10p123 URL: http://dx.doi.org/10.5539/elt.v7n10p123
}

\begin{abstract}
The purpose of this study is to explore language teachers' perspectives on Iranian third grade senior high school EFL textbook, which is prescribed by the Ministry of Education. In data collection and analysis, the researchers used theoretical sampling and the coding schemes presented in grounded theory. Final analysis yielded "Negative Evaluation of English Book 3" as the core category, and eight subcategories including "Dullness of pictures", "Disregarding Learners' Interest", "Grammar Overload", "Inadequate Explanations", "Inefficient Presentation of Pronunciation", "Contrived Dialogues" and "Decontextualized Vocabulary", and "Ignoring Language skills", which capture the teachers' perspectives on Iranian third grade senior high school EFL textbook. The results have clear implications for curriculum development, syllabus design.
\end{abstract}

Keywords: theorizing, perspectives, EFL, textbook

\section{Introduction}

More often than not textbook evaluation checklists aim at collecting quantitative information about EFL textbooks. Moreover, they are designed by researchers and syllabus designers who are alien with the actual teaching contexts. In no way do these questionaires reflect the practitioners' views. Teachers' role is to administer the checklist. To give voice to the practitioners' perspectives, the field is in need of data-driven studies which theorize teachers' perspectives concerning the strengths and weaknesses of EFL textbooks. Theory-driven textbook evaluation checklists inculcate the view that one and the same checklist can be administered across a myriad of teaching contexts. Data-driven criteria reflecting practitioners' views represent the situated-nature of syllabus evaluation. Since practitioners' perspectives have rarely been taken in to account in EFL textbook evaluation, this study aims at accounting for the situated nature of textbook evaluation by exploring teachers perspectives in an EFL context.

\section{Literature Review}

A review of textbook evaluation in Iran reveal that, they mainly aimed at: (1) developing textbook evaluation criteria (see e.g., Ansary \& Babaii, 2002); (2) evaluating EFL textbook using checklists (Jahangard, 2007; Riazi \& Aryashokouh, 2007); exploring inter-sentential relationships or evaluating textbooks at a discourse level (Darali, 2007; Tavakoli, 1995); exploring issues outside the foregoing categories (Marzban, 2005; Manafi, 2005).

Having analyzed a list of textbook evaluation checklists, Ansary and Babaii (2002) tried to extract the salient features of each scheme and develop a checklist reflecting the universal features of EFL textbooks. On the other hand, Jahangard (2007) evaluated four textbooks from high schools of Iran using a list of thirteen criteria extracted from a myriad of checklists. The analysis revealed that book four meets the established criteria while the other textbooks need major revisions before they could meet these criteria. Riazi and Aryasholouh (2007) evaluated the same textbooks to find out to what extent the vocabulary exercises raise students awareness and found that only one percent of the exercises meet this criterion. They concluded that these textbooks present isolated words rather than relating words in one way or another.

Darali (2007) studied the Spectrum series to explore the extent to which each lesson covers the cultural pragmatic knowledge of the language and found that these textbooks lacked in explicit descriptions regarding appropriateness, paralinguistic information and contextual information. Along the same lines, Tavakoli (1995) used Searle's (1976) model of speech act to analyze dialogues covered in high school textbooks in Iran and found 
that that these dialogues do not cover the commissives and declarations.

None of the above evaluations explore teachers' perspectives concerning the textbooks prescribed by central education agency in Iran. Thus there is a paucity of research on the textbook evaluation studies using data-first approaches such as Grounded Theory method. To fill in the gap, this data-driven study was conducted to explore teachers' perspectives on English book three of Iranian high schools. Being data-driven, this method best ensures the realities of each individual learning situation.

\section{Research Method}

\subsection{Participants}

The participants of this study were ten English language teachers who worked in Khorasan Razavi Province. They represented a range of educational backgrounds and previous working experiences. To ensure anonymity and confidentiality, they were assigned pseudonyms in the research report and the participants were only identifiable by their pseudonyms. The researcher sought out experienced EFL teachers - those who had been teaching for at least six years. Except for Ali and Reza, who had earned their masters' degrees in TEFL and linguistics respectively, the other practicing teachers had received their bachelors' degrees in TEFL. The study started with an open-ended interview with four experienced teacher who were willing to share their views on evaluating English Book 3 with the researcher. Analysis and coding of these first interviews shaped the subsequent questions and participants that could help develop the concepts and categories that emerged.

\subsection{Data Collection}

Participants were selected using theoretical sampling; hence the sampling process is guided by the on-going theory development (Strauss \& Corbin, 1990). Initially, however, the researcher sampled participants who were willing to share their views and experiences with the researchers. The first four participants had varied opinions regarding the research topic. Analysis of these initial interviews revealed some shared concepts. To further understand and develop a thicker description of these categories, the researcher conducted the second round of interviews with new participants of varied experience in teaching this book. New questions and hypotheses arose after analysis of each interview, so the researcher conducted the third set of interviews to further clarify emerging themes. Sampling ceased after categories were thickly described and a core categories emerged. Qualitative data were obtained through open-ended interviews so as to avoid: (1) setting limits on the range or length of responses, instead giving participants the opportunity to explain their position, feelings, or experiences; (2) inculcating the interviewers' own value judgments and biases and imposing a perspective on participants. Multiple interview rounds were used to ensure theoretical saturation (Strauss \& Corbin, 1990; 1998).

\subsection{Data Analysis}

In line with Grounded Theory, data were coded in three levels. In the first level of coding (open coding), thoughts, beliefs, feelings, and described events and relationships were flagged. Having analyzed a few interviews, transient themes or categories emerged. They were subjected to further investigation in subsequent interviews. Axial and selective coding of the data aimed at elevating the data to higher levels of abstraction; the former aimed at expanding these transient categories by specifying properties and interlinked categories while the latter aimed at specifying the core categories that relate the categories emerged during the first- and second-level coding. Following Yin (2003), the final version of emergent concepts and categories were verified through member checking to ensure the credibility of the findings.

\section{Results}

This study was set to explore and theorize senior high school English teachers' perspectives on EB3. The researcher used open-ended interviews to collect the data. The rigorous coding schemes of the grounded theory method yielded a set of categories: "Evaluation of English Book 3" as the core category and "Physical Appearance", "Vocabulary", "Reading Texts", "Exercises", "Grammar", "Pronunciation", "Dialogs", and "Skills" as the subcategories. The major themes emerged under these subcategories are explained in the following sections.

\subsection{Dullness of Pictures}

Analysis clearly shows that the physical appearance of a textbook can be affected by another factor, dullness of pictures. As noted in literature review, illustrations can be considered as the most important aspect of the design in ETL textbook. A colorful and appealing selection of the pictures is effective in terms attracting students' attention in the language learning process (Sheldon, 1988). Comparing this high school textbook with another coursebook, Amir, another teacher participant, better explains this theme: 
Pictures have major roles in the quality of the book. If you have a look at a coursebook like New Interchange, you will notice how it has attracted students' attention. We should not rely on the authors' tastes that have compiled this book several years ago, so it is time to change. If the authors used colorful pictures, they would be more appealing for students.

One of the factors which increase students' motivation for involving themselves in class activities is using colorful pictures in textbooks. Artworks should be appealing enough to motivate learners to engage in learning process. Along the same lines, Ali, another teacher participant, comments:

The pictures used in the book are not effective. They are preferable when they are colorful. Pictures are important for the students. I have noticed how funnily they express their opinions about pictures when working on exercises having interesting pictures.

Color plays a vitally important role in the world in which we live. Color can sway thinking, change actions, and cause reactions. It can act as a driving force in any learning situation. A large amount of research has been done into the effects of colors on the attention of people. Red, for example, is very effective at drawing attention. Blue on the other hand, is common and often overlooked. The color of pictures used in textbooks should be appealing to students' interest; otherwise, they can't be motivating to learning. Hassan explains:

The authors have not used colors in this textbook effectively. Colors can motivate students to learning. Blue is the only color used for pictures in this book. According to my instructor, this color doesn't attract students'attention. Red which is a bold color has no place in this book.

\subsection{Disregarding Learners' Interests}

Learners' interests should be considered in selecting reading texts for an ELT textbook since they can affect students' language learning. Analysis reveals that the textbook in question doesn't satisfy students' needs in this respect. Along the same lines, Nader comments:

Students are not interested in the topics covered in the book. We can have texts which are about scientists, athletes, famous artists, or other subjects which hold students'attention. Only the text entitled The Olympic Games do my students like. When I teach them this text, they ask questions about it signifying their positive attitude toward it.

Breen and Candlin (1987) point out that the content of an instructional material should be appropriate to the personal interests of the learners. They also emphasize that if the topics and themes expressed in the materials appeal to students' interests, the motivation level of students would increase. Ali explains this issue:

I think reading texts can be selected according to the learners' interests. I suggest the topics such as cell phones and their software, internet, play station, and games in which students have much interest. These subject areas can be more fascinating for students than those covered in the book. They can also motivate students to answer the related questions more eagerly.

\subsection{Overstating Grammar}

Textbook writers should provide students with a variety of exercises and activities to practice language items and skills. The results show that the exercises included in the textbook should not focus on grammar only. It should present the exercises comprehensively Amir explains this issue:

Most of the exercises are grammar-based and very little room is assigned to other kinds of exercises dealing with vocabulary, conversation, and pronunciation. Authors should also have used exercises dealing with synonyms/antonyms to improve students'vocabulary knowledge.

If exercises are varied, it is possible to keep students motivated and arouse their interest. Sometimes emphasis on something is justified, but too much emphasis can lead to disinterest and boredom. Along the same lines, Mahmoud comments:

The textbook is mainly grammar-based as most of the book pages are allocated to grammatical exercises and little or no room is assigned for practicing other skills. For example, conversation exercises are confined to few sentences and listening is not dealt with at all. In think if exercises are varied, students would be attracted to them; otherwise, they would be boring.

\subsection{Inadequate Explanations}

Although grammatical explanations should be presented in short units, and let the learners induce the rules from their experience of using the language, analysis reveals that these explanations are inadequate. In other words, the participants expected the authors to provide students with detailed grammatical explanations. On this issue, Amir comments: 
The explanations of grammatical points included in this textbook are too brief and it has left the supplementary items. I think that students need a complete reference section to answer their grammatical questions. If they are included, students don't have to refer to other books to satisfy their needs in this respect.

EFL materials should meet the students' needs in regard to comprehensive grammatical explanations and related examples. In other words, they should provide the learners with a reference source on grammar. Along the same lines, Mahmoud complained that they are not detailed and exemplified enough to meet students' needs:

In my view, the grammar section is acceptable, but it would be better the explanations to be more detailed and the number of examples to be increased. Students can refer to them when they have any queries about the grammatical issues.

\subsection{Inefficient Presentation of Pronunciation}

Regarding the issue of whether the book includes efficient material for pronunciation work, analysis shows that the materials for teaching pronunciation are not satisfactory and hence, do not effectively teach pronunciation. It can be attributed to not using words contextually displaying the roles of stress in words. Supporting this issue, Mohammad comments:

The pronunciation part is not considered as something practical by students as it mainly deals with the words introduced in the lower levels and few of the new words presented in this book are included in this part. If students experience stress on the new words and if they are also repeated in different parts of the lesson, students learn their applications better.

Analysis reveals that the idea of practicing pronunciation items in isolation is rejected and the priority should be given to the presentation of meaningful language items. Along the same lines, Hassan complained that the applications of pronunciation aspects have been ignored:

This part presents a few words requiring students to memorize on which syllables the stress marks lie. We teachers only classify these words in terms of the stressed syllables and students have to memorize them. So, students don't get their applications. I think students should learn the applications of the materials they are presented.

Language skills and subskills should be taught in an integrated way because language use is said to be a sort of combined skills where everything depends on everything else. Along the same lines, Reza believed that getting the pronunciation applications depends on whether it is integrated with other skills or not:

The pronunciation section has been presented in isolation and is not linked with other activities in this textbook. Accordingly, our students don't know how to use it, don't understand its relationships with other skills, and don't realize its importance.

\subsection{Contrived Dialogues}

Analysis reveals that dialogues are contrived. In other words, instead of involving students in real communication or being taken from real life situations, they involve students in practicing a dialogue made by the authors. Amir's comments better elucidate this theme:

The dialogs are not authentic. That is, they don't display normal conversational patterns. The authors have used the formal clauses and phrases not typical of normal conversational situations. I think these kinds of activities can't contribute to students'speaking proficiency.

Authentic communications involve different levels of formality. Depending on the situation, authentic dialogues are formal or informal. The dialogues covered in this textbook, on the other hand, are solely formal. Mahmoud's comments better explain this shortcoming:

The sentences used in these parts are confined to formal ones. We know that informal expressions are generally used in conversations. They seem unnatural and dissimilar to real ones. The authors should have supported these parts with relevant CD's and films. They can show the common conversations happening in real life situations.

It is essential to examine whether the content of the speaking materials is consistent with the real-life reflections since such usages enhances natural communication (Mc Donough \& Shaw, 1993). Mina explains this theme:

I wonder why they have included this part in the book since it mainly presents conversations happening out of real contexts displaying unreal situations. We all know that if our students experience natural learning situations, they will acquire them better.

\subsection{Decontextualized Vocabulary}

Considering the presentation of vocabulary in the textbook, a context such as sentences, paragraphs, and texts is 
essential for presenting the vocabulary since they often help students understand the meaning of the word, phrase, etc. Mahmoud believed that better learning the new words depends on whether they are contextualized or not:

As some of the new words of this book are abstract, they need to be defined and exemplified, but they are not considered in this book. I suggest that all of them should be contextualized so as to avoid students' recourse to their Persian equivalents and help them learn their applications better.

Each word has its own context, and for each context the word has a specific meaning. That is, meaning always changes from one context to another. Analysis reveals that the vocabulary should be presented in contexts. Nader's comments better elucidate this shortcoming:

All English teachers believe that words should not be presented out of contexts since they have different meanings in different situations. Considering the word match, it has different meanings in different contexts. If contextualized, its meanings become evident.

\subsection{Vocabulary Overload}

The time allotted to teach a particular textbook and the level of the learners for whom the textbook is written can determine its vocabulary load. The data analysis reveals that these two factors should be taken into consideration. Reza better explains this theme:

A great number of new words are assigned for each lesson in this book. It's a hard work to teach them all in just two hours a week. I sometimes hold extra sessions to remedy this problem. In my opinion, vocabulary load should be decided on in terms of students' level. I think it can be suitable for students majoring in math or natural sciences, but not for students of other majors.

Along the same lines, Ahmad also confirmed that there should be a relationship between the vocabulary load of the textbook and the level of the students for whom the textbook has been written. He comments:

The large number of new words included in this book is just suitable for the students majoring in mathematics, but not for all since math students' level is higher than that of other students majoring in other fields.

Vocabulary should be presented by a variety of techniques and they should be varied and combined according to the learner's individual needs and preferences. Moreover, there should be a relationship between the number of new words included in the textbook and the time allotted for teaching the textbook. Analysis reveals that time constraints force teachers to stick to just one technique, i.e. translation to present the new words. Moslem's comments elucidate this shortcoming:

There are about sixty new words in each lesson to be taught. Due to time limitation, it is impossible for teachers to teach them using different techniques such as performing pantomime or using pictures. For this reason, teachers have to translate them into Persian.

\subsection{Exclusive Focus on Reading}

According to Dahmardeh (2009), teaching four language skills has also been emphasized as one of the main aims of the national curriculum. However, careful analysis of the curriculum document suggests that its main concern is about reading comprehension and grammar. On this issue, Amir comments:

Although the book is centered on reading, students don't have a good command of it. Is it justified to spend thousands of hours on teaching English for nothing? It may have different reasons, one of which may be the inappropriate focus of English language teaching program in our country.

In Iran, all the textbooks for schools are produced by the Ministry of Education and its main concern in English language teaching is to improve reading comprehension. Analysis indicates that as the book focus is on reading, the teachers' aim is to improve students' reading comprehension. Ali explains this theme:

Ministry of Education aims at developing students' reading comprehension. I think this can be an appropriate orientation. So I try to develop students' vocabulary knowledge and improve their reading comprehension thereafter.

\section{Discussion and Conclusion}

This study explored English teachers' perceptions concerning third grade senior high school EFL textbook to be used in Iran high schools. The aim of the study was to find out in what ways the teachers were evaluating the textbook EB3. In terms of collecting data, interviews were carried out with English teachers. The results showed that the teacher participants' perspectives about $E B 3$ were mostly negative.

Now it would be useful to depict the striking points in terms of the participants' suggestions for improvement of 
this textbook and its shortcomings respectively. The participants indicated that the physical appearance of this textbook should be improved, the texts should be updated and informative, the exercises are required to be varied and comprehensive, the skills ought to be evenly presented, the dialogs should be authentic, the vocabulary had better to be contextualized, pronunciation ought to be applied, and grammar should not be overemphasized. Considering the shortcomings of the textbook, the teachers stated that physical appearance of the book is not so satisfactory that they can appeal to students. Moreover, the new vocabulary of the book is not presented effectively because of its overload and inefficient presentation, and the grammar is overemphasized. In addition, pronunciation section is mainly concerned with stress on isolated words and no exercises have been given to students to practice them. Considering the skills, speaking skills is not emphasized, listening is totally neglected, but reading was focused. Most of reading texts were also stated as being outdated. Moreover, dialogs were believed to be inauthentic and including formal patterns of conversation. The last but not least, time constraints were indicted having negative effects on teachers' work.

To sum up, although research findings are abundant in materials development and syllabus design, practitioners' perspectives have rarely been taken into account. Criteria derived from teachers' perspectives complement the common textbook evaluation checklist because while the former presents the situated nature of syllabus evaluation, the latter presents universally applicable criteria.

\section{References}

Ansary, H., \& Babaii, E. (2002). Universal characteristics of EFL/ESL textbook: A step towards systematic textbook evaluation. The Internet TESL Journal, 2, 1-8. Retrieved from http://iteslj.org/Articles/Ansary-Textbooks/

Breen, P. M., \& Candlin, N. C. (1987). Which materials? a consumer's and designer's guide. In L. E. Sheldon (Ed.), ELT textbooks and materials: Problems in evaluation and development. ELT Documents 126. London: Modern English Publications.

Brown, S. C. (1999). Learning across the campus: How college facilitates the development of wisdom (Unpublished doctoral dissertation). University of Maryland, College Park.

Dahmardeh, M. (2009). Communicative textbooks: English language textbooks in Iranian secondary school. Linguistik online, 40, 4. Retrieved from http://www.linguistik-online.de/40_09/index.html

Darali, G. (2007). Pragmatics dimension in Spectrum textbooks (Unpublished master's thesis). Shiraz University, Iran.

Glaser, B. G. (1992). Basics of grounded theory analysis: Emergence vs. forcing. Mill Valley, CA: Sociology Press.

Glaser, B. G., \& Strauss, A. L. (1967). The discovery of grounded theory: Strategies for qualitative research. Chicago: Aldine.

Jahangard, A. (2007). The evaluation of the EFL materials taught at Iranian public high schools. Karen's Linguistics Issues. Retrieved October, 2008, from http://www3.telus.net/linguisticsissues/bymonth.html

Manafi, A. (2005). Evaluation of the place of peace and war in Iranian guidance school textbooks content in 2005-2006 (Unpublished master's thesis). Shahid Beheshti University, Tehran, Iran.

Marzban, P. (2005). Evaluation of primary school textbooks content with regard to the views and perspectives in Islamic Republic of Iran cultural developmental programs (Unpublished master's thesis). Alzahra University, Tehran, Iran.

McDonough, J., \& Shaw, C. (1993). Materials and methods in ELT. Oxford: Blackwell.

Miles, M. B., \& Huberman, A. M. (1984). Qualitative Data Analysis. Newbury Park, CA: Sage.

Riazi, A. M., \& Aryashokouh, A. (2007). Lexis in English textbooks in Iran: Analysis of exercises and proposals for consciousness-raising activities. Pacific Association of Applied Linguist, 11, 17-34.

Sheldon, L. (1988). Evaluating ELT textbooks and materials. English Language Teaching Journal, 42(4), 237-246.

Strauss, A., \& Corbin, J. (1990). Basics of qualitative research: Grounded theory procedures and techniques. Newbury Park, CA: Sage Publications.

Strauss, A., \& Corbin, J. (1998). Basics of qualitative research: Techniques and procedures for developing grounded theory. Thousand Oaks, CA: Sage Publications.

Tavakoli, F. (1995). Functional analysis of the dialogues in the Iranian senior high school English textbooks (Unpublished master's thesis). Allameh University, Tehran. 
Yin, R. K. (2003). Case study research: Design and methods. Thousand Oaks, CA: Sage.

\section{Copyrights}

Copyright for this article is retained by the author(s), with first publication rights granted to the journal.

This is an open-access article distributed under the terms and conditions of the Creative Commons Attribution license (http://creativecommons.org/licenses/by/3.0/). 